\title{
A Unique Case of Trueperella Pyogenes Causing Hepatic Abscesses in Pigeons
}

\author{
P. M. Priya ${ }^{2,}$ Abhinay Gontu ${ }^{1}$, R. Ambily ${ }^{2}$ and Siju Joseph ${ }^{2}$ \\ ${ }^{1}$ Indian Immunologicals Limited, Hyderabad, Andhra Pradesh, India \\ ${ }^{2}$ College of Veterinary and Animal Sciences, Mannuthy, Thrissur, Kerala, India
}

Received 2 November 2012; Accepted 21 February 2013; Published 27 February 2013

Academic Editor: Shinji Takaï

\begin{abstract}
The present study reports the identification of the etiology for hepatic abscesses leading to heavy mortality in pigeons from Thrissur, Kerala. The cultural and biochemical characteristics confirmed the isolate as Trueperella pyogenes. The high antibiotic resistance and pathogenecity studies in mice demonstrated the ability of the isolated bacteria to cause death in affected birds.
\end{abstract}

Keywords: Trueperella pyogenes, American fan tailed pigeons, Hepatic abscess.

\section{Introduction}

Trueperella pyogenes (previously, Corynebacterium pyogenes) is an opportunistic pathogen, causing suppurative infections in a wide range of hosts, including avians (Barbour et al., 1991) and domestic animals (Addo et al., 1977). It is known to spread hematogenously to cause abscesses and suppurative lesions in various organs and tissues (Tolle et al., 1983). This organism has been reported to cause liver abscesses in large animals like cattle (Narayanan et al., 1998), but its role as an etiological agent for hepatic abscesses in birds like pigeons is yet to be established. The present study reports the isolation and characterization of
Trueperella pyogenes from a hepatic abscess in an american fan tailed pigeon.

\section{Materials and Methods}

A commercial flock of American-fan tailed pigeons from Thrissur, Kerala was presented with heavy morbidity and mortality. A detailed post-mortem examination of a representative bird, revealed air-sacculitis accompanied by hepatitis and abscesses on the dorsal side of the liver. The tissue and associated material from the hepatic abscess was collected and cultured on- Blood agar, Brain heart infusion (BHI) agar and Mac Conkey agar by incubation at $37^{\circ} \mathrm{C}$ for $48 \mathrm{hrs}$ under both aerobic and anaerobic conditions.

Copyright (C) 2013 P. M. Priya, Abhinay Gontu, R. Ambily and Siju Joseph. This is an open access article distributed under the Creative Commons Attribution License unported 3.0, which permits unrestricted use, distribution, and reproduction in any medium, provided that original work is properly cited. Contact author: Abhinay Gontu E-mail: abhinay_vet@yahoo.co.in

How to Cite this Article: P. M. Priya, Abhinay Gontu, R. Ambily and Siju Joseph, " A Unique Case of Trueperella Pyogenes Causing Hepatic Abscesses in Pigeons," International Journal of Veterinary Medicine: Research \& Reports, vol. 2013, Article ID 486054, 3 pages DOI: $10.5171 / 2013.486054$ 
The isolation and characterization by biochemical tests was done by standard tests (Barrow and Feltham, 1993). The antibiotic sensitivity of the isolate to common antibiotics was tested by an antibiogram (Bauer et al., 1966). Further, the pathogenecity of the isolate was successfully demonstrated in Balb/c mice (Kan et al., 2009). The test was carried out with various $\log$ dilutions of the basic culture $\left(10^{-6}, 10^{-7}\right.$, $10^{-8}$ and $10^{-9}$ ) in $0.5 \mathrm{ml}$ saline administered via two routes; intra-venous and subcutaneous in mice.

\section{Results}

The organisms cultured under anaerobic conditions were observed as rough shaped, creamy colonies on blood agar and BHI agar. The colonies were observed to show $\beta$ hemolysis on blood agar. Further, the isolate was identified to be gram-positive pleomorphic non-motile cocco-bacillary organisms. The organisms were characterized to be negative for catalase, oxidase, urease and citrate utilization. These nitrate non-reducing organisms were positive for indole production and were found to be fermenting glucose, lactose, maltose, trehalose, xylose and raffinose but not sucrose, mannitol, salicin, sorbitol, mellibiose and arabinose. The isolated culture was hence identified as Trueperella pyogenes. The isolate was identified to be sensitive for streptomycin and chloramphenicol and resistant to regular antibiotics like amoxicillin, ampicillin, ceftriaxone, gentamicin, tetracycline, sulphadiazine, gatifloxacin, enrofloxacin, ciprofloxacin, tobramycin and polymixin B. Further, the isolate was demonstrated to be highly pathogenic by causing death to mice in by intra-venous administration in a dosedependant reaction. Death was observed within four hours of administering the highest concentration of $10^{-6}$ dilution. The least tested dilution of $10^{-9}$ of the isolate could cause death within $24 \mathrm{hr}$ of administration. The reaction to the subcutaneous administration of the isolate was also observed to be dose-dependant. Abcesses were observed within 24 hours of sub-cutaneous inoculation with $10^{-6}$ and $10^{-7}$ dilutions of $T$. pyogenes. The weaker dilutions, $10^{-8}$ and $10^{-9} \mathrm{CFU}$ could cause abscesses within $72 \mathrm{hr}$ of administration.

\section{Discussion}

Trueperella pyogenes is a gram positive, pleomorphic and facultative anaerobe reported to cause suupurative and pyogenic infections (Brinton et al., 1993; Reddy et al., 1982). The characterization of the isolate by its cultural, growth and biochemical characteristics confirmed the organism as $A$. pyogenes. Similar reports for identification were reported by Wust et al., 1993 and Narayanan et al., 1998. The isolate was identified to be resistant to most of the regular antibiotics. The ability of the organisms to cause pyogenic abcesses and their highly pathogenic nature demonstrated in mice, proved them to cause death in the affected birds. The present study presents a highly pathogenic $A$. pyogenes, which needs to be further characterized to help prevent further economic losses.

\section{References}

Addo, P. B. \& Dennis, S. M. (1977). "Corynebacteria Associated with Diseases of Cattle, Sheep and Goats in Northern Nigeria," British Veterinary Journal, 133 (4) 334-339.

Barbour, E. K., Brinton, M. K., Caputa, A., Johnson, J. B. \& Poss, P. E. (1991). "Characteristics of Actinomyces Pyogenes Involved in lameness of Male Turkeys in North-Central United States," Avian Diseases, 35(1) 192-196.

Barrow, G. I. \& Feltham, R. K. A. (1993). Cowan and Steel's Manual for the Identification of Medical Bacteria, Cambridge University Press, Australia.

Bauer, A. W., Kirby, W. M. M., Sherris, J. C. \& Turck, M. (1966). 'Antibiotic Susceptibility 
3 International Journal of Veterinary Medicine: Research \& Reports

Testing by a Standardized Single Disc Method,' American Journal of Clinical Pathology, 45(4) 493-496.

Brinton, M. K., Schellberg, L. C., Johnson, J. B., Frank, R. K., Halvorson, D. A. \& Newman, J. A. (1993). "Description of Osteomyelitis Lesions Associated with Actinomyces Pyogenes Infection in the Proximal Tibia of Adult Male Turkeys," Avian Diseases, 37(1) 259-262.

Kan, I. Y., Blum, S. \& Elad, D. (2009). 'Synergism between Porphyromonas Levii and Trueperella Pyogenes in a Murine Abscess Model,' Israel Journal of Veterinary Medicine, 64(3) 1-7.

Narayanan, S., Nagaraja, T. G., Wallace, N., Staats, J., Chengappa, M. M. \& Oberst, R. D. (1998). "Biochemical and Ribotypic Comparison of Actinomyces Pyogenes and Actinomyces Pyogenes-Like Organisms from Liver Abscesses, Ruminal Wall, and Ruminal Contents of Cattle," American Journal of Veterinary Research, 59(4) 271-276.

Reddy, C. A., Cornell, C. P. \& Fraga, A. M. (1982). "Transfer of Corynebacterium Pyogenes (Glage) Eberson to the Genus Actinomyces as Actinomyces Pyogenes (Glage) Comb. Nov.," International Journal of Systemic Bacteriology, 32(4) 419-429.

Tolle, A., Franke, V. \& Reichmuth, J. (1983). "Corynebacterium Pyogenes Mastitis Bacteriological Aspects," Deutsche tierärztliche Wochenschrift, 90(7) 256-260.

Wust, J., Lucchini, G. M., Luthy-Hottenstein, J., Brun, F. \& Altwegg, M. (1993). "Isolation of Gram-Positive Rods that Resemble but are Clearly Distinct from Actinomyces Pyogenes from Mixed Wound Infections," Journal of Clinical Microbiology, 31(5) 1127-1135. 